University of Nebraska - Lincoln

DigitalCommons@University of Nebraska - Lincoln

Sociology Department, Faculty Publications

Sociology, Department of

2019

Partner congruence on fertility intentions and values: Implications

for birth outcomes

Karina M. Shreffler

Stacy Tiemeyer

Julia McQuillan

Arthur L. Greil

Tiffany Spierling

Follow this and additional works at: https://digitalcommons.unl.edu/sociologyfacpub

Part of the Family, Life Course, and Society Commons, and the Social Psychology and Interaction Commons

This Article is brought to you for free and open access by the Sociology, Department of at DigitalCommons@University of Nebraska - Lincoln. It has been accepted for inclusion in Sociology Department, Faculty Publications by an authorized administrator of DigitalCommons@University of Nebraska - Lincoln. 


\title{
Partner congruence on fertility intentions and values: Implications for birth outcomes
}

\author{
Karina M. Shreffler, ${ }^{1}$ Stacy Tiemeyer, ${ }^{1}$ Julia McQuillan, ${ }^{2}$ Ar- \\ thur L. Greil, 3 and Tiffany Spierling ${ }^{1}$ \\ 1 Oklahoma State University \\ 2 University of Nebraska-Lincoln, \\ 3 Alfred University \\ Corresponding author - Karina M. Shreffler, Department of Human Development and Family Science, \\ Oklahoma State University, 700 N Greenwood Ave, Tulsa, Oklahoma 74106, USA. \\ Email: karina.shreffler@okstate.edu
}

\begin{abstract}
In heterosexual couples, both partners' intentions to have a baby (or not) are associated with the likelihood of a subsequent birth, yet most studies only measure women's intentions. Therefore, little is known about the potential association of couple agreement or disagreement on intentions or on such values as importance of parenthood, career, and leisure and the implications for childbearing. The goal of this article is to assess whether couple-level agreement or disagreement in fertility intentions and values are associated with the likelihood of a subsequent birth. Guided by the Theory of Conjunctural Action, we use couple data from two waves of the U.S. National Survey of Fertility Barriers for our analysis. Based on logistic regression analysis, we find that if either partner intends a child, the odds of having a baby within 3 years are higher than if neither partner intends and that the odds are substantially higher when both partners intend a child. Couples in whom both partners and couples in whom only the woman has a high value on career success are less likely to have a baby. Our findings suggest that agreement on fertility intentions is associated with considerably higher birth probability and that values about
\end{abstract}

Published in Journal of Social and Personal Relationships 36:8 (2019), pp 2307-2322. DOI: $10.1177 / 0265407518787232$

Copyright (C) 2018 Karina M. Shreffler, Stacy Tiemeyer, Julia McQuillan, Arthur L. Greil, and Tiffany Spierling. Published by SAGE Publications. Used by permission. 
life domains matter as well. Couple disagreement on intentions and values are related in different ways to birth outcomes depending on which partner holds which value as important. Using data from both partners allows us to examine the patterns of couple agreement, values, and gendered influences related to birth outcomes.

Keywords: Couples, fertility intentions, gender, pregnancy, values

Ensuring that every person is born healthy and wanted is a vital public health goal; therefore, accurately identifying factors associated with birth or lack of birth is important (Macaluso et al., 2010; Mosher, Jones, \& Abma, 2012). Although it is an imperfect indicator, women's fertility intentions (i.e., intending to have a child or not) are the strongest predictor of women's birth outcomes (i.e., having a child or not) (Miller, Rodgers, \& Pasta, 2010; Westoff \& Ryder, 1977). However, conception is usually the result of a dyadic process. Partners could disagree about their intentions to have a baby or not, and partners can influence each other's intentions and preferences (Stein, Willen, \& Pavetic, 2014). Yet most research on fertility behavior and unintended fertility has focused on women only (for exceptions, see Coombs \& Chang, 1981; Thomson, 1997). When men's intentions are reported, they are usually retrospective and are based on women's reports (Thomson, 1997). To truly understand the modifiable predictors of fertility outcomes, men's intentions and values should be included in couple-level analyses (Stein et al., 2014; Stykes, 2015).

Unintended pregnancies often have worse outcomes (e.g., preterm birth, low birth weight) than intended pregnancies (Hall, Benton, Copas, \& Stephenson, 2017). For each couple, there is only one birth outcome (e.g., having a baby or not); therefore, if partners disagree about their intentions, at least one partner did not intend the outcome. Because partner fertility desires (Thomson, 1997) and experiences (Benyamini, Gozlan, \& Kokia, 2009) can differ, efforts to align fertility desires with fertility outcomes (e.g., desiring a child or not and having a child or not) are most comprehensive when they include both partners. The theory of conjectural action (Johnson-Hanks, Bachrach, Morgan, \& Kohler, 2011) provides a framework for understanding how partners could have different fertility intentions and behaviors based upon different values, expectations, or attitudes that might influence childbearing timing or birth outcomes (e.g., McQuillan, Greil, Shreffler, \& Bedrous, 2015; Rackin \& Bachrach, 2016). For 
example, partners can differ in how much they value parenthood, leisure, and career success and how much they perceive having a child will support or challenge their priorities (McQuillan, Greil, Shreffler, \& Tichenor, 2008). Few studies, however, include male partner values and attitudes or examine whether partner agreement or disagreement are differentially associated with fertility outcomes (Stein et al., 2014).

In this study, we use couple data from two waves of the National Survey of Fertility Barriers (NSFB) to explore how initial congruence or lack of congruence and direction of intentions and values are associated with the likelihood of a subsequent birth 3 years later. We compare couples in which both partners intend a child to those in which only one partner does or neither do and assess whether intentions are associated with having a birth or not, even after adjusting for congruence and direction of valuing parenthood, leisure, and career success (e.g., both think parenthood is important) plus control variables.

\section{Literature review}

\section{Couple agreement/disagreement and implications for having a birth or not}

Reproductive technology is expanding possibilities for ways to conceive a child (Franklin, 2013), but conception still usually involves two people in a heterosexual couple relationship. There is a long-standing recognition of the importance of examining the childbearing intentions of both partners in the study of fertility outcomes (e.g., Beckman, Aizenberg, Forsythe, \& Day, 1983; Thomson, 1997). Yet due to survey challenges and cost considerations, there have been few fertility studies including the intentions, decisions, or behaviors from both partners in a married or cohabiting union. Even though most studies of fertility intentions and behaviors have focused solely on women, there is evidence that women's intentions may not provide a good proxy for couple-level intentions. Stykes (2015), for example, found that women often underestimated their partners' intentions and that men's intentions may be a better proxy for couple intentions than women's intentions.

Self-reports from both partners in a couple have revealed considerable disagreement on fertility intentions within couples. 
Hohmann-Marriott (2009) found that approximately one third of couples who were asked about their intentions for a specific birth had incongruent birth intentions. In couples with mismatched intentions, there was higher risk of adverse outcomes (e.g., inadequate prenatal care and more preterm births). Disagreement is particularly common among disadvantaged, minority couples (Williams, 1994) and among cohabiting couples as compared to married couples (Hohmann-Marriott, 2009). Studies of which partner's preferences prevail when there is disagreement have provided inconsistent findings. Some studies found that women have more power in family formation/fertility decisions (Thomson, 1997; Townes, Beach, Campbell, \& Wood, 1980), while others found equal influence over fertility outcomes (Jansen \& Lifbroer, 2006) or that men's preferences have more influence on couple outcomes (Stein et al., 2014).

Early fertility research focused more on objective statuses (e.g., level of education, employment, age, relationship status) than the subjective meanings of life course and social statuses (Johnson-Hanks et al., 2011). There has been an increasing integration of women's attitudes and values into fertility research. For example, women who reported more traditional gender attitudes (Barber, 2001) and greater religiosity (Hayford \& Morgan, 2008) tended to have higher fertility intentions (e.g., greater desire to have a baby) and give birth at a younger age. Women with higher importance of motherhood report higher intentions, women with higher importance of career and leisure report lower fertility intentions (McQuillan et al., 2015), and women with higher importance of career are less likely have a subsequent birth (Shreffler \& Johnson, 2013).

The few extant studies that examine men's values and attitudes have found that they also matter for fertility intentions and outcomes, and sometimes in different ways than they do for women. Men in relationships with women tend to place a high importance on fatherhood (Tichenor, McQuillan, Greil, \& Shreffler, 2011). Yet research has been mixed on how more traditional gender ideology is associated with men's fertility intentions, with one study finding lower reported intentions (Kaufman, 2000) and another finding higher fertility intentions (Shreffler, Pirretti, \& Drago, 2010) among men. Further, even when studies examine both men's and women's attitudes or values regarding childbearing, they might focus on individual-level outcomes rather than the combined influence of patterned perspectives on fertility 
outcomes (e.g., Roberts, Metcalfe, Jack, \& Tough, 2011) or use one partner's report of another partner's attitudes rather than data from couples (e.g., Shreffler et al., 2010).

Prior research suggests that the intentions and values of both partners in heterosexual couples can influence whether couples have a birth. The degree to which births are the outcome of couple, versus his or her intentions and values, is less clear. Yet prior research and the theory of conjunctural action (TCA) suggest that a couple outcome such as a birth is best understood as the result of couple-level intentions and attitudes.

\section{Theoretical perspective}

Recent theoretical work suggests that we should view conception as more than a single conjuncture, asserting that the events leading to conception and eventual birth present multiple opportunities for action or inaction (Miller, 2011). Three theoretical models have been proposed to describe the process of fertility decision-making: the Traits- Desires-Intentions-Behavior (TDIB) (Miller, 1994, 2011), the Theory of Planned Behavior (TPB) (Ajzen \& Klobas, 2013; Dommermuth, Klobas, \& Lappegard, 2011), and TCA (Bachrach \& Morgan, 2013; Johnson-Hanks et al., 2011; Rackin \& Bachrach, 2016). These three models, while compatible with one another, draw our attention to different aspects of the reproductive decision-making process. The TDIB can be distinguished from other theoretical approaches in its attention to underlying genetically based motivations to have or not have children (Basten \& $\mathrm{Gu}, 2013$ ). The TPB represents a general approach to the explanation of intentional, reasoned, action (Ajzen, 1991, 2005), which has been applied to reproductive decision-making (Ajzen \& Klobas, 2013; Dommermuth et al., 2011). What distinguishes the TPB from other theoretical approaches is its concern with the underlying cognitive structure of fertility decisions.

TCA combines prior theories of fertility (e.g., TDIB, TPB) with considerations drawn from the life-course perspective, cognitive science, and systems theory. (Bachrach \& Morgan, 2013; Johnson-Hanks et al., 2011). TCA posits that fertility behavior is the result of both conscious and deliberative intentions and nondeliberative, emotionally laden "automatic" cognitions. The model posits that cognitions derive from social structures, which include both material structures 
and schemas (e.g., values, beliefs, norms, scripts, and ways of categorizing). Schemas are shaped by background factors, experience, and life-course transitions. Social cognitive schemas function as a prism for interpretations of social context, norms, proscriptive behavior, and motivations associated with childbearing (Bachrach \& Morgan, 2013; Johnson-Hanks et al., 2011). Of the three models of fertility intentions, TCA places the most emphasis on social cognitive schemas and is thus suitable for a study that examines both intentions and social values.

TCA emphasizes schemas or the meanings that people use to interpret their worlds and to illuminate variations in fertility experiences. From a TCA framework, social circumstances (e.g., relationship status, turning an age that is normative for childbearing, valuing career success, completing education) can make having a baby more or less salient and, therefore, change the meaning of having a baby or not. Prior couple congruence research has emphasized the role of couple congruence for coping with stressful couple experiences such as infertility, coronary disease, or cancer (see Peterson, Newson, \& Rose, 2003). Couple congruence or lack of congruence regarding fertility intentions and values provide a relationship context that is likely to matter for the likelihood of couples having a birth. Couples in which both partners intend a child should have higher odds of having a birth than couples in which only one or neither partner intends a child. Among women, higher importance of parenthood is associated with higher fertility intentions (McQuillan et al., 2015); thus, we anticipate that if both parents have high importance of parenthood, the couple is likely to have higher odds of having a child. Leisure (McQuillan et al., 2008) and career demands (Hakim, 2003) can compete with childrearing for women, and more recently for men (Milkie, Mattingly, Nomaguchi, Bianchi, \& Robinson, 2004). Therefore, couples in which both partners place a high value on leisure or career success should have lower odds of having a child than couples in which only one or neither partner places a high value on leisure or career success.

\section{Statement of the problem}

To meet the goal that all births be wanted, it is important to go beyond the individual to the couple contexts of births. Our goal is, therefore, to address the gap in information regarding how couple agreement or disagreement in fertility intentions and other attitudes/ 
values is associated with fertility outcomes, particularly with contemporary data. Further, it is unclear whether couple disagreements on values regarding parenthood or career might affect outcomes differently, depending upon whether the male or female partner reports greater agreement with a particular value. There are very few data sets that include self-reports of intentions and values from both partners (married and cohabiting) with follow-up data on births years later. The NSFB provides the necessary data; it includes surveys with both women and their partners who are men, fertility plans, desires, and fertility relevant values/attitudes as well as follow-up data on births (or the absence of birth).

\section{Data and methods}

The NSFB is a random-digit-dialing telephone survey with a probability-based sample of 4,787 U.S. women aged 25-45 during the years 2005-2006 (Wave 1) with follow-up interviews 3 years after the initial interview, roughly occurring between 2008 and 2009 (Wave 2). Interviews were also conducted at Wave 1 with about $20 \%$ of partners of the main respondents to permit analyses of couple-level data. The sample is nationally representative and includes an oversample of Census central office codes with a high minority population to ensure sufficient numbers of women for subgroup analyses. Information about the study design and measures can be accessed at https:// www.icpsr.umich.edu/icpsrweb/DSDR/studies/36902\#bibcite. The public-access data files can be accessed at https://www.icpsr.umich. edu/icpsrweb/DSDR/studies/36902\#bibcite. Extensive comparisons with Census data indicate that the weighted sample is representative of women aged 25-45 in the U.S. Women whose partners responded to the NSFB survey were similar to women whose partners did not respond, but they were more likely to be married, White, less traditional in terms of gender roles, and less likely to have male partners who were surgically sterile (Slauson-Blevins \& Johnson, 2016).

We first restricted the sample to women who had partners who completed the Wave 1 interview $(n=928)$. Next, we restricted the sample to women who completed both interviews at both waves ( $n$ $=690$ ). Finally, respondents were asked whether they were still with the same partner who was reported at Wave 1 , and we selected only 
couples who were together at both waves $(n=626)$. We excluded respondents in same-sex relationships. Four cases had missing data; two of these cases were missing data for female respondent's education, and two of the cases were missing data for male partner's importance of parenthood. We used conditional mean imputation to replace missing values in these four instances.

The sample for this analysis includes all heterosexual couples ( $n=$ 624) who responded to questions about fertility intentions in both waves. Women in the sample were between 25 and 45 years old at the time of the interview, and their partners were between 20 and 63 years old. At Wave 1, parity (number of previous live births) ranged between o and 3 or more, and about 31\% of the sample did not have children at Wave 1 . The majority of the sample was married (96\%). The length of time couples reported living together ranged from 0 years to 34 years, and on average, the respondents reported living together for 8.85 years. Overall, women in the sample reported 15 years of education, on average. White respondents made up the majority of the sample (83\%), followed by $7 \%$ Hispanic women, 6\% who were classified as other race/ethnicity, and $4 \%$ of the sample was classified as Black. For bivariate analyses, we used $\chi^{2}$ for categorical variables and $t$ tests for continuous variables to compare differences among couples who gave birth between waves and those who did not. Logistic regression $\chi^{2}$ models were utilized to examine couple-level intentions and attitudes at Wave 1 on the likelihood of a birth between Waves 1 and 2.

\section{Measures and constructs}

The dependent variable, birth, is an indicator variable with 1 indicating that the female respondent gave birth between waves and o indicating that the respondent did not give birth between waves.

Our study incorporated four couple-level focal independent variables measured at Wave 1: fertility intentions, importance of parenthood, importance of career, and importance of leisure. Couple-level fertility intentions were measured using both partners' responses to the following question: "Do you intend to have a baby?" Respondents who said yes were coded as 1, and respondents who said no or don't know were coded as o. We combined responses for the couple to create 
a variable with four categories: neither intends, both intend, female only intends, and male only intends.

Both women and their partners responded to questions about attitudes and values. The importance of parenthood scale (Cronbach's $\alpha=.77$ ) was developed by McQuillan, Greil, Shreffler, and Tichenor (2008) and is calculated using the mean values of five questions, with a range from $1=$ strongly disagree to $4=$ strongly agree, where 4 indicates high importance of parenthood. The 5 items include (1) "Having children is important to my feeling complete as a woman," (2) "I always thought I would be a parent," (3) "I think my life will be or is more fulfilling with children," and (4) "It is important for me to have children." The response categories for the fifth (5) "How important is each of the following in your life ... raising children?" range from not very important to very important. We recoded each partner's responses on the scale to indicate a high value (the grand mean of all respondents and their partners, 3.26 or higher on a 4-point scale) of importance of parenthood $=1$. We used the grand mean for the scale because the cutoff of the scale was less obvious compared to other single-item scales used in our study. We constructed the couple-level variable with four categories: both low importance of parenthood, both high importance of parenthood, only female high importance of parenthood, and only male high importance of parenthood.

Both partners were asked: "How important is each of the following to you in your life?" Importance of career is indicated by the response to the question: "Being successful in my line of work?" Importance of leisure is indicated by the response to the question: "Having leisure time to enjoy my own interests." Response categories ranged from $1=$ not important to $4=$ very important. For the variables indicating importance of career and importance of leisure, we recoded responses for each partner as a dummy variable of 1 indicating very important, with any other response as o. Similar to the other couple-level variables, we then created couple context variables for both career and leisure with four categories: both low importance, both high importance, only female high importance, and only male high importance.

We also included several control variables in analyses. Because women with fertility problems might be unable to meet their fertility intentions, we include a dummy variable indicating subfecundity at Wave 1. Subfecundity was constructed from responses of two 
questions: (1) "Was there ever a time when you were trying to get pregnant but did not conceive within 12 months?" or (2) "Was there ever a time when you regularly had sex without using birth control for a year or more without getting pregnant?" Women who answered yes to either question were coded as 1 . All of our analyses controlled for age of both partners at Wave 1, measured in years. We also included a measure of parity at Wave 1, which was constructed from reports of live births prior to the first wave. Parity ranged from o = no live births to 3 = three or more live births. We included parity in our analyses because previous births have been found to influence intentions and the probability of future births (Schoen, Astone, Kim, Nathanson, \& Fields, 1999). In addition to parity, we included a dummy variable indicating whether a female respondent's partner has children from a previous union. Our models also included an indicator of whether the couple was married at Wave 1 and a variable indicating the number of years they have been living together in the same household (the survey instrument did not differentiate the length of the relationship, however). Female respondent's level of relationship happiness was constructed from the response of the question, “Taking all things together, how would you describe your relationship? Would you say that it is very happy, pretty happy, or not too happy?" Women who responded "very happy" were coded as 3, "pretty happy" as 2, and "not too happy" as 1. We use the raw score in analyses. We use female's education level, measured in years at Wave 1 in our models. We created three indicator variables for race: Black, Hispanic, and other compared to White women, the referent group. Individuals who reported Hispanic/Latino ethnicity were classified according to coding rules that gave first priority to identification as "Hispanic" and second priority to identification as "Black."

\section{Results}

Mean and standard deviations of the primary independent variables are included in Table 1 , with $\chi^{2}$ and $t$ tests indicating significant differences on study variables between those who did not give birth between waves and those who did. Of the couples who had a baby between waves, most were couples in which both partners intended to 
Table 1. Descriptive statistics for couples by birth between waves $(n=624)$.

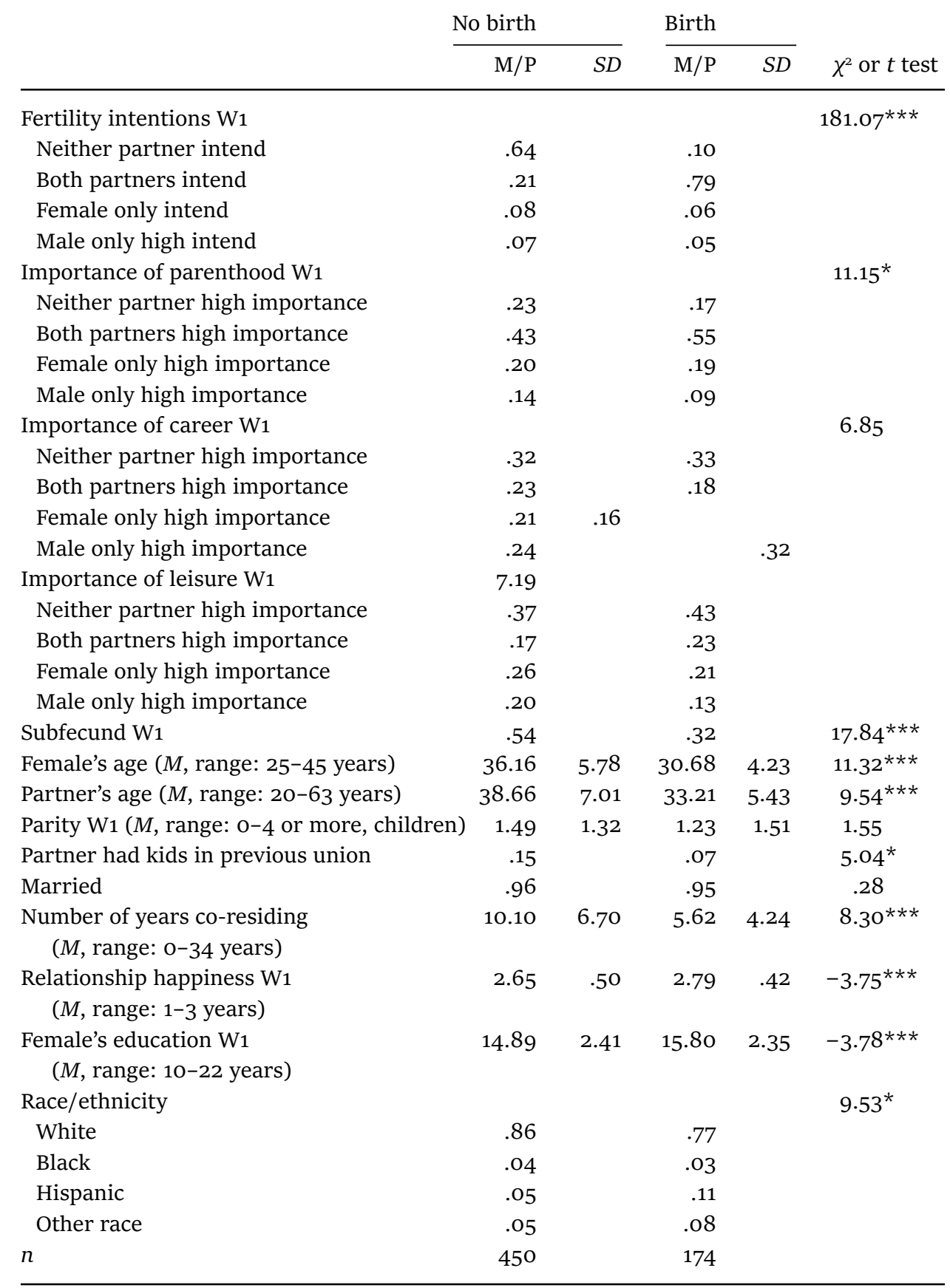

Note. $\mathrm{W} 1=$ Wave $1 ; \mathrm{M} / \mathrm{P}=$ mean or proportion; $\mathrm{SD}=$ standard deviation.

${ }^{*} p<.05$

$* * p<.01$

$* * * p<.001$ 
have a baby (79\%); only 10\% of births were to couples in which neither partner intended a child. Fewest births were to couples in which only the male $(6 \%)$ or female $(5 \%)$ partner intended a child. Most of the couples who did not intend a birth did not have one (64\%), but a substantial portion of those who did not have a baby was couples in which both partners intended a child. Similar to the couples who had a baby, among those who did not, the same proportion was couples in which only the men $(7 \%)$ or women $(8 \%)$ intended a child. Therefore, couple agreement and intentions are both significantly associated with outcomes $\left(\chi^{2}=181.08, p<.001\right)$.

More couples who had a baby consisted of partners who agreed that parenthood is important (55\%) than couples who did not have a baby ( $43 \%)$. Among the couples who had a baby, more were "women only" high parenthood importance (19\%) than "men only" (9\%). Importance of parenthood and couple agreement is significantly associated with a birth between waves. Roughly the same percentage of couples with a birth and without a birth reported that neither partner placed a high importance on career (32\% and 33\%, respectively) or both placed a high importance on career $(23 \%$ and $18 \%$, respectively), although the latter pattern is a little more consistent with competing priorities. The pattern is reversed for leisure; $21 \%$ of the couples with a birth between waves were couples in whom only the woman reported a higher level of importance of leisure, compared to $13 \%$ where only the man reported a higher level of importance of leisure. Neither measures of couple congruence on importance of career or leisure was significantly associated with a birth between waves.

Nearly a third of the couples with a birth between waves had experienced some level of fertility problems prior to Wave 1, compared to $54 \%$ of couples without a birth, a statistically significant difference $\left(x^{2}=17.84, p<.001\right)$. As expected, couples with a birth between waves were on average significantly younger (women: $M=30.68, S D$ $=4.23, t$ test $=11.32, p<.001$; men: $M=33.21, S D=5.43, t$ test $=9.54$, $p<.001$ ) and had fewer children compared to those without a birth between waves. About $15 \%$ of couples who did not report a birth between waves reported that their partners had children in a previous union compared to $7 \%$ of those who had a birth between waves ( $x^{2}=$ $5.04, p<.05)$. Nearly all of the respondents were married, but, on average, those who had a birth together had been co-residing about half 
as long as couples who did not report a birth ( $t$ test $=8.30, p<.001$ ). At Wave 1, women who would go on to report a birth between waves reported being significantly lower levels of happiness $(M=2.65)$ than women who did not give birth between waves $(M=2.79, t$ test=_3.75, $p<$.001). Women who did not give birth had slightly lower levels of education (difference of less than 1 year, $t$ test $=\_3.78, p<.001$ ) and were more likely to be White $\left(x^{2}=9.53, p<.05\right)$.

Table 2 presents odds ratios (ORs) from logistic regression analyses examining the relationships between couple agreement on fertility intentions, attitudes, and Wave 2 fertility outcomes. Model 1 includes fertility intentions and control variables (i.e., subfecundity at Wave 1, age of each partner, parity, whether male partner has children from a previous union, union type, length of co-residence, female partner's relationship happiness, female partner's education, and race/ethnicity). Compared to couples in whom neither partner intended a birth at Wave 1, couples in whom both intended a birth had more than 16 times higher odds of having a baby (OR $=16.06$, $p<.001)$. As anticipated, even when only one member of the couple intended to have a(nother) child in the future, the odds of a birth between waves were significantly higher than when neither partner intended a birth (only female partner intended OR $=3.63, p<$. 01; only male partner intended $\mathrm{OR}=3.64, p<.05$ ). The female partner's age was associated with lower odds of a birth between waves $(\mathrm{OR}=.91, p<.05)$. Parity was also associated with higher odds of a birth between waves (OR $=1.37, p<.05$ ). Not surprisingly, couples who reported a fertility problem at Wave 1 had lower odds of a birth between waves (OR $=.52, p<.05)$. Hispanic women were over twice as likely to report a birth between waves (OR $=2.58, p<.05$ ).

Model 2 includes the couple-level measure of importance of parenthood, career, and leisure plus control variables (but not intentions). The associations of couple incongruence in values with the likelihood of a birth between waves varied. Results indicate that births were more likely for couples with agreement on high importance of parenthood (OR $=3.07, p<.01$ ). Similarly, when both partners valued career success, births were less likely ( $\mathrm{OR}=.42, p<.05$ ). Incongruence in values of leisure mattered; if men had a high value on leisure, couples were less likely to have a baby between waves. Our findings suggest that congruence matters for birth outcomes, but when values 
Table 2. Logistic regression model estimating birth between waves

\begin{tabular}{|c|c|c|c|}
\hline & $\begin{array}{r}1 \\
\text { OR }\end{array}$ & $\begin{array}{r}2 \\
\text { OR }\end{array}$ & $\begin{array}{r}3 \\
\text { OR }\end{array}$ \\
\hline \multicolumn{4}{|l|}{ Fertility intentions $\mathrm{W} 1$} \\
\hline \multicolumn{4}{|l|}{ Neither partner intends (ref) } \\
\hline Both partners intend & $16.06 * * *$ & & $15.61 * * *$ \\
\hline Only female intends & $3.63^{* *}$ & & $3.15^{*}$ \\
\hline Only male intends & $3.64^{*}$ & & $3.81^{*}$ \\
\hline \multicolumn{4}{|l|}{ Importance of parenthood W1 } \\
\hline \multicolumn{4}{|l|}{ Neither partner high importance (ref) } \\
\hline Both high importance & & $3.07^{* *}$ & 1.88 \\
\hline Only female high importance & & 2.15 & 1.75 \\
\hline Only male high importance & & 1.36 & .85 \\
\hline \multicolumn{4}{|l|}{ Importance of career $\mathrm{W} 1$} \\
\hline \multicolumn{4}{|l|}{ Neither partner high importance (ref) } \\
\hline Both high importance & & $.42^{*}$ & $.34^{*}$ \\
\hline Only female high importance & & .51 & $.46^{*}$ \\
\hline Only male high importance & & 1.12 & .74 \\
\hline \multicolumn{4}{|l|}{ Importance of leisure $\mathrm{W} 1$} \\
\hline \multicolumn{4}{|l|}{ Neither partner high importance (ref) } \\
\hline Both high importance & & .96 & .99 \\
\hline Only female high importance & & .86 & 1.00 \\
\hline Only male high importance & & $.43^{*}$ & .52 \\
\hline Subfecund at W1 & $.52^{*}$ & $.53^{*}$ & $.49^{*}$ \\
\hline Age (centered) & $.91^{*}$ & $.86 * * *$ & $.89^{*}$ \\
\hline Partner's age (centered) & 1.01 & 1.00 & 1.01 \\
\hline Parity W1 (centered) & $1.37^{*}$ & 1.05 & 1.30 \\
\hline Male partner had kids in previous union & 1.18 & .95 & 1.44 \\
\hline Married & 1.49 & 1.26 & 1.52 \\
\hline Number of years co-residing (centered) & .96 & $.94^{*}$ & .97 \\
\hline Relationship happiness & 1.65 & $1.76^{*}$ & $1.74^{*}$ \\
\hline Female's education W1 years (centered) & 1.09 & $1.17^{* *}$ & 1.12 \\
\hline \multicolumn{4}{|l|}{ Race/ethnicity } \\
\hline \multicolumn{4}{|l|}{ White (ref) } \\
\hline Black & .74 & 1.24 & .98 \\
\hline Hispanic & $2.58^{*}$ & $4 \cdot 45^{* * *}$ & $3 \cdot 54^{* *}$ \\
\hline Other race & .61 & .74 & .55 \\
\hline$N$ & 624 & 624 & 624 \\
\hline
\end{tabular}

Note. $\mathrm{W} 1$ = Wave $1 ; \mathrm{OR}=$ odd ratio; $($ ref $)=$ reference category.

${ }^{*} p<.05$
${ }^{* *} p<.01$
$* * * p<.001$ 
reflect more traditional gender ideologies or behaviors such as believing women should be primary caregivers and men the primary breadwinners in the family (Marks, Bun, \& McHale, 2009), or gendered differences in leisure patterns (Dush, Yavorsky, \& Schoppe- Sullivan, 2018), births were more likely.

When all variables were included in the model (Model 3), fertility intentions and importance of career success remained significant predictors of a birth. In the full model, importance of parenthood was no longer significant.

\section{Discussion}

Despite awareness that integrating fertility information from both partners in a couple should provide richer information for understanding couple experiences of fertility, few studies have applied a couple approach due to data limitations. Situating couple fertility intentions within the context of values and attitudes of both partners and the level of partner congruence also adds insights that are not available when women alone are the focus. The primary goal of this study, therefore, was to explore how couple-level agreement in fertility intentions and values are associated with the likelihood of a subsequent birth. Our findings suggest that couple congruence on fertility intentions is strongly associated with dyadic outcomes such as having a birth (e.g., if both partners intended a child, the couple was much more likely to have one than if only one partner or neither intended). When both partners or women only reported high importance of parenthood, the odds of a birth were higher, but the association was explained by fertility intentions. Similarly, when both partners or women alone reported a high value on career success, odds of having a child were lower than for couples with other career values. Unlike the negative association of valuing leisure and lower importance of motherhood for women in Model 2, in the full model valuing leisure was not associated with having a child for any congruence configuration. Therefore, congruence and direction of intentions or values were associated with the odds of having a birth, but not for all of the values that we anticipated.

Compared to couples who both agreed that they did not intend a birth at Wave 1, those who agreed on intending had 15 times higher 
odds of giving birth in the 3 years between survey interviews. Couples in whom one partner intended to have a baby but the other did not were more than three times as likely to give birth as couples in whom neither partner intended a birth. Couples in whom both partners described parenthood as very important and in couples in whom only the woman claimed parenthood was very important were significantly more likely to give birth, but the association was mediated by the addition of fertility intentions variables in the final model. The importance of leisure only mattered when men valued leisure highly but that also was no longer significant when fertility intentions were added in the final model. The only value variable that remained significant across models was career importance; when both partners rated career as very important, and when women only rated their careers as very important, their odds of giving birth were about half what it was when neither partner rated career as very important. The association of importance of career with having a child or not could reflect values or it could reflect the need for income and the ability to maintain income with a child.

This study contributes in several ways to our understanding of couple-level fertility intentions for fertility outcomes. First, whereas the majority of prior studies focus on women's reports of their partners' fertility intentions (Stykes, 2015), we included each partner's own intentions, which allowed us to determine the extent of agreement and disagreement between partners' fertility intentions. Further, in the few recent studies of couple-level intentions and couple mismatch (e.g., Hohmann-Marriott, 2009; Stykes, 2015), the fertility intentions of the mother and father regarding the birth of the target child were reported 9 months after the birth of the child. Yet prior research has recognized that fertility intentions are best captured before a pregnancy, as parents are likely to revise their intentions to indicate a pregnancy was intended (Joyce, Kaestner, \& Korenman, 2002). Our data captured prospective fertility intentions. In addition, we extended our focus beyond fertility intentions to include attitudes about life domains that have previously been found to compete with or support childbearing as well as couple agreement and disagreement on those domains. Prior research has indicated that valuing parenthood (McQuillan et al., 2015), career success (Shreffler \& Johnson, 2013), and leisure (Barber, 2001) have implications for fertility intentions and/or birth outcomes, but those studies included only women 
in their analyses. Using data from male and female partners allowed us to examine the patterns of couple agreement or not and gendered norms. Finally, we drew upon a national, longitudinal sample of childbearing-aged women and their partners: the NSFB. The data set included extensive questions about fertility plans, preferences, and behaviors in both waves as well as a variety of questions that allowed us to probe different dimensions of women's and their partner's attitudes and plans. This allowed us not only to examine how couple agreement on intentions and values affects outcomes but also to determine how the preferences of men and women matter for fertility outcomes when they disagree. The two waves of data allowed us to examine how intentions and attitudes at one time point are associated with the likelihood of a birth within a 3-year time span following the first interview.

This study is not without limitations. First, measuring fertility intentions is by no means a straightforward task. There is much debate as to how to best measure fertility intentions (Philipov \& Bernardi, 2011). As is the case with any measure based on self-reports, we cannot be sure that respondents' answers completely reflect their attitudes. Because fertility intentions and values may not be stable over time, we cannot be certain that we would have obtained the same results if measures had been recorded at a different time. Second, even with longitudinal data, one must be very cautious about drawing causal conclusions from correlational data. The variables that are included within the models may not account for all factors that may be related to birth outcomes, such as difficulty conceiving or carrying a pregnancy to term. Moreover, there is likely more variability among the couples who did not have a baby between waves of the survey; though they are lumped together in the dependent variable, this group includes both couples who already met their fertility preferences and those who decided not to have a baby (either during the 3-year period or forgoing parenthood altogether). Third, while our sample was probability-based, male participants were eligible for inclusion only if they were partnered to women already in the study; thus our sample of men may not be fully representative of the population. Attrition over time may also affect the representativeness of our sample. Fourth, our analysis does not take into account pregnancies that did not result in a birth. Fifth, we did not have data regarding the actual fertility decision-making process. 
This study raises interesting questions pertaining to disagreement and birth outcomes and implications for practice and research. For example, among couples who disagreed and a birth ultimately happened, it would be interesting to determine whether one partner was able to persuade the other to have a baby, or if a pregnancy that might have been unplanned was less likely to end in abortion due to the desires of one partner. Bauer and Kneip (2013) suggest that future studies should explore the bargaining power of partners as it relates to attitudinal preferences and fertility outcomes. The results suggest implications for practice; couples should be encouraged to discuss their fertility intentions and values before pregnancy. Among those who are pregnant, it may be important for practitioners to ascertain intendedness from both partners. Our findings begin to elucidate how couple agreement on intentions and values matters for birth outcomes, but many questions remain. When disagreements arise regarding childbearing plans or attitudes/values that might compete with or increase the likelihood of childbearing, how are they resolved? Does one partner have more influence than the other partner? How stable are fertility intentions and attitudes or values across time? Do partners' intentions and attitudes about childbearing become more aligned over time, or do they stay the same? Future research with couple-level data across multiple time points is necessary to answer these questions.

\section{Authors' note}

The content is solely responsibility of the authors and does not necessarily represent the official views of the National Institutes of Health. An earlier version of this article was presented at the Population Association of America annual meeting in 2016 (Washington, DC).

\section{Funding}

The author(s) disclosed receipt of the following financial support for the research, authorship, and/ or publication of this article: This work was supported by the Eunice Kennedy Shriver National Institute of Child Health and Human Development (David Johnson, PI) under grant Ro1- HDo44144 and by the National Institute of General Medical Sciences (Jennifer Hays-Grudo, PI) of the National Institutes of Health under grant P2OGM109097.

\section{Open research statement}

This research was not pre-registered. The data and materials used in the research are available upon request by emailing karina.shreffler@okstate.edu. 


\section{References}

Ajzen, I. (1991). The theory of planned behavior. Organizational Behavior and Human Decision Processes, 50, 179-211.

Ajzen, I. (2005). Attitudes, personality, and behavior (2nd ed.). Maidenhead, England: Open University Press.

Ajzen, I., \& Klobas, J. (2013). Fertility intentions: An approach based on the theory of planned behavior. Demographic Research, 29, 203-231.

Bachrach, C. A., \& Morgan, S. P. (2013). A cognitive-social model of fertility intentions. Population and Development Review, 39, 459-485.

Barber, J. S. (2001). Ideational influences on the transition to parenthood: Attitudes toward childbearing and competing alternatives. Social Psychology Quarterly, 64, 101-127.

Basten, S., \& Gu, B. (2013). Childbearing preferences, reform of family planning restrictions, and the low fertility trap in China. Working Paper 61. Oxford Centre for Population Research Working Paper. Department of Social Policy and Intervention, University of Oxford.

Bauer, G., \& Kneip, T. (2013). Fertility from a couple perspective: A test of competing decision rules on proceptive behavior. European Sociological Review, 29, 535-548.

Beckman, L. J., Aizenberg, R., Forsythe, A. B., \& Day, T. (1983). A theoretical analysis of antecedents of young couples' fertility decisions and outcomes. Demography, 20, 519-533.

Benyamini, Y., Gozlan, M., \& Kokia, E. (2009). Women's and men's perceptions of infertility and their associations with psychological adjustment: A dyadic approach. British Journal of Health Psychology, 14, 1-16. doi:10.1348/135910708X279288

Coombs, L. C., \& Chang, M. C. (1981). Do husbands and wives agree? Fertility attitudes and later behavior. Population and Environment, 4, 109-127.

Dommermuth, L., Klobas, J., \& Lappega ${ }^{\circ}$ rd, T. (2011). Now or later? The theory of planned behavior and timing of fertility intentions. Advances in Life Course Research, 16, 42-53.

Dush, C. M. K., Yavorsky, J. E., \& Schoppe-Sullivan, S. J. (2018). What Are Men Doing while Women Perform Extra Unpaid Labor? Leisure and Specialization at the Transitions to Parenthood. Sex Roles, 78, 715-730.

Franklin, S. (2013). Biological relatives: IVF, stem cells, and the future of kinship. Durham, NC: Duke University Press.

Hakim, C. (2003). A new approach to explaining fertility patterns: Preference theory. Population and Development Review, 29, 349-374.

Hall, J. A., Benton, L., Copas, A., \& Stephenson, J. (2017). Pregnancy intention and pregnancy outcome: Systematic review and meta-analysis. Maternal and Child Health Journal, 21, 670-704.

Hayford, S. R., \& Morgan, S. P. (2008). Religiosity and fertility in the United States: The role of fertility intentions. Social Forces, 86, 1163-1188. 
Hohmann-Marriott, B. (2009). The couple context of pregnancy and its effects on prenatal care and birth outcomes. Maternal and Child Health Journal, 13, 745-754.

Jansen, M., \& Lifbroer, A. C. (2006). Couples' attitudes, childbirth and the division of labor. Journal of Family Issues, 7, 1487-1511.

Johnson-Hanks, J. A., Bachrach, C. A., Morgan, S. P., \& Kohler, H. P. (2011). The theory of conjunctural action. In Understanding Family Change and Variation, (pp. 1-22). Dordrecht, Netherlands: Springer.

Joyce, T., Kaestner, R., \& Korenman, S. (2002). On the validity of retrospective assessments of pregnancy intention. Demography, 39, 199-213.

Kaufman, G. (2000). Do gender role attitudes matter? Family formation and dissolution among traditional and egalitarian men and women. Journal of Family Issues, 21, 128-144.

Macaluso, M., Wright-Schnapp, T. J., Chandra, A., Johnson, R., Satterwhite, C. L., Pulver, A., . . Pollack, L. A. (2010). A public health focus on infertility prevention, detection, and management. Fertility and Sterility, 93, 16.e1-16.e10.

Marks, J. L., Lam, C. B., \& McHale, S. M. (2009). Family patterns of gender role attitudes. Sex Roles, 61, 221-234.

McQuillan, J., Greil, A. L., Shreffler, K. M., \& Bedrous, A. V. (2015). The importance of motherhood and fertility intentions among women in the United States. Sociological Perspectives, 58, 20-35.

McQuillan, J., Greil, A. L., Shreffler, K. M., \& Tichenor, V. (2008). The importance of motherhood among women in the contemporary United States. Gender and Society, 22, 477-496.

Milkie, M. A., Mattingly, M. J., Nomaguchi, K. M., Bianchi, S. M., \& Robinson, J. P. (2004). The time squeeze: Parental statuses and feelings about time with children. Journal of Marriage and Family, 66, 739-761.

Miller, W. B. (1994). Childbearing motivations, desires, and intentions: A theoretical framework. Genetic, Social, and General Psychological Monographs, $120,223-258$.

Miller, W. B. (2011). Differences between fertility desires and intentions: implications for theory, research and policy. Vienna Yearbook of Population Research, 9, 75-98.

Miller, W. B., Rodgers, J. L., \& Pasta, D. J. (2010). Fertility motivations of youth predict later fertility outcomes: A prospective analysis of national longitudinal survey of youth data. Biodemography and Social Biology, 56, 1.

Mosher, W. D., Jones, J., \& Abma, J. C. (2012). Intended and unintended births in the United States: 1982-2010. National Health Statistics Reports, 55, 1-28.

Peterson, B. D., Newton, C. R., \& Rosen, K. H. (2003). Examining congruence between partners' perceived infertility-related stress and its relationship to marital adjustment and depression in infertile couples. Family Process, 42, 59-70. 
Philipov, D., \& Bernardi, L. (2011). Concepts and operationalisation of reproductive decisions: Implementation in Austria, Germany and Switzerland. Comparative Population Studies, 36, 495-580.

Rackin, H. M., \& Bachrach, C. A. (2016). Assessing the predictive value of fertility expectations through a cognitive-social model. Population Research and Policy Review, 35, 527. doi:10. 1007/s11113-016-9395-z

Roberts, E., Metcalfe, A., Jack, M., \& Tough, S. C. (2011). Factors that influence the childbearing intentions of Canadian men. Human Reproduction, 26, 12021208. doi:10.1093/humrep/ deroo7

Schoen, R., Astone, N. M., Kim, Y. J., Nathanson, C. A., \& Fields, J. M. (1999). Do fertility intentions affect fertility behavior? Journal of Marriage and the Family, 61, 790-799.

Shreffler, K. M., \& Johnson, D. R. (2013). Fertility intentions, career considerations and subsequent births: The moderating effects of women's work hours. Journal of Family and Economic Issues, 34, 285-295.

Shreffler, K. M., Pirretti, A. E., \& Drago, R. (2010). Work-family conflict and fertility intentions: Does gender matter? Journal of Family and Economic Issues, 31, 228-240.

Slauson-Blevins, K., \& Johnson, K. M. (2016). Doing gender, doing Surveys? Women's gatekeeping and men's non-participation in multi-actor reproductive surveys. Sociological Inquiry, 86, 427-449.

Stein, P., Willen, S., \& Pavetic, M. (2014). Couples' fertility decision-making. Demographic Research, 30, 1697-1731.

Stykes, J. B. (2015). Couples' fertility intentions: Measurement, correlates, and implications for parent and child well-being. Unpublished Dissertation, Bowling Green State University.

Thomson, E. (1997). Couple childbearing, desires, intentions, and births. Demography, 34, 343-354.

Tichenor, V., McQuillan, J., Greil, A. L., \& Shreffler, K. M. (2011). The importance of fatherhood to U.S. married and cohabiting men. Fathering, 9, 232-251.

Townes, B. D., Beach, L. R., Campbell, F. L., \& Wood, R. L. (1980). Family building: A social psychological study of fertility decisions. Population and Environment, 3, 210-220.

Westoff, C. F., \& Ryder, N. B. (1977). The predictive validity of reproductive intentions. Demography, 14, 431-453.

Williams, L. B. (1994). Determinants of couple agreement in US fertility intentions. Family Planning Perspectives, 26, 169-174. 